\title{
Optimization of ICP-OES'S parameters for uranium analysis of rock samples
}

\author{
Xiaozhe $\mathrm{Li}^{1}$. Chao Xiong ${ }^{2} \cdot \mathrm{Kun} \mathrm{Sun}^{1} \cdot$ Fang Fang $^{1}$ - Qingxian Zhang ${ }^{1}$
}

Received: 3 November 2020 / Revised: 10 December 2020 / Accepted: 22 December 2020 / Published online: 31 March 2021

(c) The Author(s) 2021

\begin{abstract}
Currently, the quantitative analysis methods for uranium that are widely used in laboratories, such as the volumetric method and inductively coupled plasma mass spectrometry (ICP-MS) cannot achieve low cost, simple operation, and little influence by other elements. The inductively coupled plasma optical emission spectrometer (ICP-OES) has a wide linear range, and high stability, and can be used to identify multiple elements simultaneously. However, when ICP-OES is used for quantitative analysis of uranium, the settings for the RF power, nebulizer flow, and pump rate can affect the analysis results. In this work, these parameters were carefully optimized for identifying uranium. Based on experiments, we selected two spectrum peaks $409.014 \mathrm{~nm}$ and $424.167 \mathrm{~nm}$ for quantitative analysis with the lowest interference. The optimal parameters obtained are atomizer flow rate of $0.75 \mathrm{~L} / \mathrm{min}$, a sample pumping rate of $1.6 \mathrm{~mL} / \mathrm{min}$, and a high-frequency power of $1400 \mathrm{~W}$. Then we compared the accuracy of the volumetric method, ICP-MS method and ICP-OES method with the optimized parameter for analysis of experimental samples and references. The results showed that the ICP-OES with the optimized parameters proposed in this paper can be used to perform a convenient, quick, and efficient quantitative analysis of uranium in minerals.
\end{abstract}

Keywords ICP-OES · Uranium concentration · Optimal parameters

\section{Introduction}

The quantitative analysis of uranium in minerals is the foundation for uranium exploration, environment evaluation, and radiation contamination.

The widely used quantitative analysis of uranium includes gamma spectroscopy, X-ray fluorescence, atomic absorption spectrometry (AAS), inductively coupled plasma mass spectrometry method (ICP-MS) and so on. Ammonium vanadate redox titration is often used to measure the uranium content in rock samples in China, where the uranium is reduced to a tetravalent state with divalent iron after decomposition of the sample with phosphoric acid, oxidation of excess divalent iron with nitric acid, destruction of excess nitric acid with urea, and finally titration of tetravalent uranium with

Chao Xiong

170241113@qq.com; 82774063@qq.com

1 The College of Nuclear Technology and Automation Engineering, Chengdu University of Technology, Chengdu 610059, China

2 School of Nuclear Science and Engineering, East China University of Technology, Nanchang 330013, China a standard solution of ammonium vanadate using sodium diphenylamine sulfonate as an indicator. Different analysis methods are used with samples of different contents [1-5]. However, some difficulties like tedious pretreatment and complicated process, and high cost at faced. The gamma spectroscopy method is a semi-quantitative analysis method and is widely used to geological logging. With the AAS method, only monochromatic light in the atomic spectrum can be applied, so only one element at a time can be detected [6]. ICP-MS has high sensitivity and low detection limit, but it is only suitable for analyzing mineral samples with lowconcentration-level uranium for the instruments ranges that cannot meet the requirements [3, 7-9]. ICP-MS is complicated to perform and requires precise adjustment, which is not conducive to improving the efficiency of sample testing.

The ICP-OES has a wide linear range [10]. Therefore, it is a fast analysis method with low-cost and high efficiency [11]. Thus it has been widely used in qualitative and quantitative analysis of minerals during geological exploration, such as rare poly-metallic ores, water sediments, soil, and feldspar [12].

When ICP-OES is applied for the quantitative analysis of uranium in mineral samples, the condition of RF power, 
atomizer flow rate, and sample pumping rate will affect the accuracy of results $[13,14]$. In order to improve the accuracy of the ICP-OES for the uranium, this paper selects the optimal wavelength of the spectrum peaks after analyzing the spectral line of uranium; by adjusting the RF power, atomizer flow rate and sample pumping rate respectively, the standard series of uranium concentration gradients are measured. Then the results are compared and analyzed so that the three parameters are optimized. Apart from that, ICP-OES, ICP-MS, and volumetric methods are used to determine the references to verify the optimization effect.

\section{Experimental}

\subsection{Reagents}

Purified water was used for samples and standard solutions, which were ion-exchanged and re-distilled. Water $(\geq 18.2$ $\mathrm{M} \Omega$ ) was used in sample preparation.

The standard uranium solution was prepared from $\mathrm{U}_{3} \mathrm{O}_{8}$ a reference. The $\mathrm{U}_{3} \mathrm{O}_{8}$ reference with a purity higher than $99.99 \%$ was dried at $900{ }^{\circ} \mathrm{C}$ for $2 \mathrm{~h}$. Then $1.1794 \mathrm{~g}$ of $\mathrm{U}_{3} \mathrm{O}_{8}$ was dissolved into $1000 \mathrm{~mL}$ water. The uranium concentration in the reserve liquid was $1000 \mu \mathrm{g} / \mathrm{mL}$. The solution was diluted to $1 \mathrm{mg} / \mathrm{L}, 5 \mathrm{mg} / \mathrm{L}$ and $10 \mathrm{mg} / \mathrm{L}$ standard solution. The other reagents in the experiments were analytical pure reagent. The instrument used was an Optima 5300 DV inductively coupled plasma emission spectrometer made by PerkinElmer, U.S.A.

\subsection{Sample preparation}

(1) A sample with $0.1000 \mathrm{~g} \mathrm{U} 3 \mathrm{O} 8$ was placed in a Poly tetra fluoroethylene (PTFE) crucible and wet with water. Then $1.0 \mathrm{~mL}$ of nitric acid, $2.0 \mathrm{~mL}$ of perchloric acid, and $10.0 \mathrm{~mL}$ of hydrofluoric acid were added into the PTFE crucible, after which was heated on a hot plate at $160-170{ }^{\circ} \mathrm{C}$.

(2) When the sample produced a large amount of white perchlorate smoke, the temperature of the hot plate was raised so that the perchloric acid fully digest the organics in the samples. This step was not finished until no more perchlorate smoke was produced.

(3) One $\mathrm{mL}$ of nitric acid and water was need to clean the sidewalls of crucible, after which the crucible was heated on a hot plate at low temperature to dissolve the sample. Two or four drops of hydrochloric acid were added and heating was continued. When the crucible was removed from the hot plate after wet salt had been formed.

(4) Four $\mathrm{mL}$ of nitric acid and $10-15 \mathrm{~mL}$ of water were added to the sample, and a transparent solution was formed. If no insoluble matter was presented, 2-4 drops of hydrochloric acid were added and heating was continued until a transparent solution has been formed. Then solution was diluted to $100 \mathrm{~mL}$.

\subsection{Instrument and conditions}

The instrument used a 5300DV inductively coupled plasma emission spectrometer (Perkin Elmer, U.S.A), the operation conditions were a radiofrequency $(\mathrm{RF})$ power of 1200-1400 W, a working frequency of $40.68 \mathrm{MHz}$, a wavelength range of $165-782 \mathrm{~nm}$, a wavelength resolution accuracy of $\pm 0.1 \mathrm{~nm}$; the optical resolution was $0.006 \mathrm{~nm}$ (at $200 \mathrm{~nm}$ ); the atomizer flow was $0.70-0.85 \mathrm{~L} / \mathrm{min}$, the auxiliary gas flow of $0.2 \mathrm{~L} / \mathrm{min}$, the plasma gas flow rate was $15 \mathrm{~L} / \mathrm{min}$, and the sample pumping rate was $1.2-1.8 \mathrm{~mL} /$ min. The reading delay time was $30 \mathrm{~s}$, the cleaning time was $30 \mathrm{~s}$, measurements were repeated for 3 times, and the plasma observation method was an axial observation.

\section{Results and discussion}

Three peak positions are needed in the ICP-OES analysis of uranium. The most intense peak is at $409.014 \mathrm{~nm}$. The second peak is at $424.167 \mathrm{~nm}$, and the last peak is at $367.007 \mathrm{~nm}$, which is close to $367.003 \mathrm{~nm}(\mathrm{Fe}), 367.006 \mathrm{~nm}$ (Th), and $367.021 \mathrm{~nm}(\mathrm{Ca})$. Fe is the major element in rock, and uranium is often accompanied by thorium. In this experiment, the wavelengths of $409.014 \mathrm{~nm}$ and $424.167 \mathrm{~nm}$ were chosen for the analysis.

As can be seen from the Fig. 1, in the experimental environment described above, when ICP-OES is used for analysis and measurement, the interference of adjacent spectral lines with the spectrum peak of the target element can be avoided, which makes it highly sensitive. According to the correlation coefficients of the recommended wavelength of the element to be measured, such as the SNR, spectral intensity, relative sensitivity, etc., provided by the line library of the inductively coupled plasma emission spectrometer, the optimal measuring wavelength was found to be $409.014 \mathrm{~nm}$ and $424.167 \mathrm{~nm}$ by linear regressions.

\subsection{Optimization experiment of instrument parameters}

Table 1 shows that the main parameters of general ICP-OES for uranium analysis are the RF power, atomizer flow rate, and sample pumping rate [14]. The proposed parameters for the experiments in this research is shown in Table 2.

In the experiment, standard solutions with uranium concentrations of $0 \mathrm{mg} / \mathrm{L}, 1 \mathrm{mg} / \mathrm{L}, 5 \mathrm{mg} / \mathrm{L}$, and $10 \mathrm{mg} / \mathrm{L}$ were used to build a standard curve, and reference samples were 

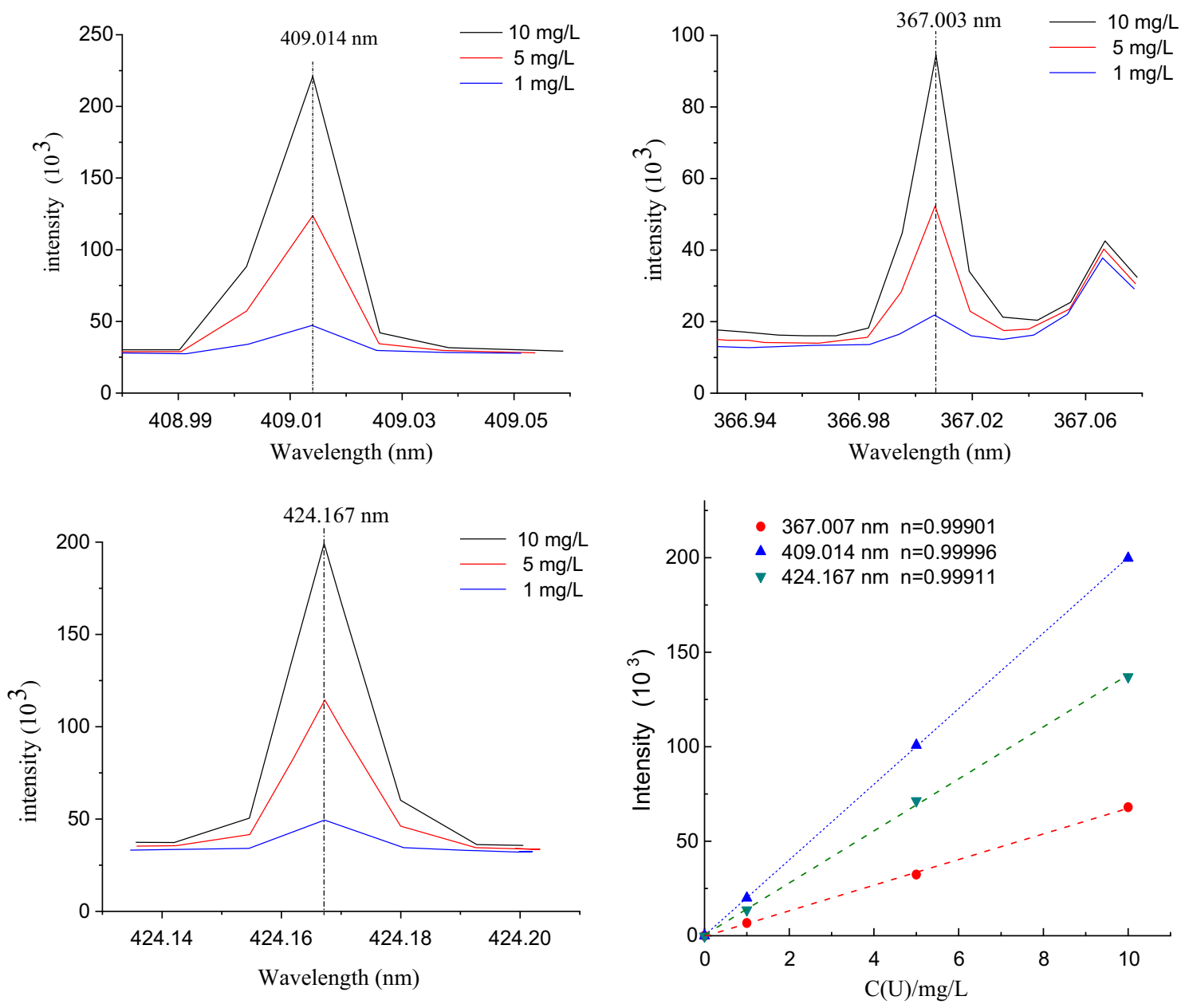

Fig. 1 Three spectrum peaks at different concentrations

Table 1 Main parameters of the ICP-OES for uranium analysis

\begin{tabular}{llll}
\hline $\begin{array}{l}\text { Optimize instru- } \\
\text { ment parameters }\end{array}$ & RF power $(\mathrm{W})$ & $\begin{array}{l}\text { Atomizer flow } \\
\text { rate }(\mathrm{L} / \mathrm{min})\end{array}$ & $\begin{array}{l}\text { Pump rate } \\
(\mathrm{mL} / \mathrm{min})\end{array}$ \\
\hline Example 1 & 1200 & 0.70 & 1.2 \\
Example 2 & 1300 & 0.80 & 1.5 \\
Example 3 & 1400 & 0.90 & 1.8 \\
\hline
\end{tabular}

used to verify the method. The experiment was performed using the nine groups of the parameters in Table 2. Each group of the experiments was repeated three times to determine the average of uranium concentration. The standard deviation analysis of the experimental results was carried out by measuring the relative deviation between the mean value and the standard value obtained using the volumetric method. The results were listed in Table 3.

Table 3 shows that three parameters influenced the accuracy and those three parameters have impacts from high to low on the nebulizer flow, pump rate, and RF power. The RF
Table 2 Proposed parameters of the ICP-OES for uranium analysis

\begin{tabular}{llll}
\hline Number & RF power $(\mathrm{W})$ & $\begin{array}{l}\text { Atomizer flow rate } \\
(\mathrm{L} / \mathrm{min})\end{array}$ & $\begin{array}{l}\text { Pump rate } \\
(\mathrm{mL} / \mathrm{min})\end{array}$ \\
\hline 1 & 1200 & 0.7 & 1.8 \\
2 & 1200 & 0.8 & 1.5 \\
3 & 1200 & 0.9 & 1.2 \\
4 & 1300 & 0.7 & 1.2 \\
5 & 1300 & 0.8 & 1.8 \\
6 & 1300 & 0.9 & 1.5 \\
7 & 1400 & 0.7 & 1.5 \\
8 & 1400 & 0.8 & 1.2 \\
9 & 1400 & 0.9 & 1.8 \\
\hline
\end{tabular}

power was fixed at $1400 \mathrm{~W}$, and the flow rate of the atomizer and the sample pump rate were optimized.

The parameter that impacted the atomizer flow was the temperature of the central plasma channel, the residence time of the sample in the plasma channel, and the 
atomization efficiency of the solution. When the RF power was fixed at $1400 \mathrm{~W}$ a sample pumping rate of $1.5 \mathrm{~mL} / \mathrm{min}$ and atomizer flow rates of $0.7 \mathrm{~L} / \mathrm{min}, 0.75 \mathrm{~L} / \mathrm{min}, 0.8 \mathrm{~L} / \mathrm{min}$, $0.85 \mathrm{~L} / \mathrm{min}$ were selected for experiments. The results for the reference samples are shown in Table 4.

From Table 4, when the concentration in the references were $0.194 \%$ and $0.703 \%$, the standard deviation at an atomizer flow rate of $0.75 \mathrm{~L} / \mathrm{min}$ was the smallest. Therefore, the optimal atomizer flow rate in the experiments was $0.75 \mathrm{~L} /$ min.

The sample pumping rate mainly impacts the injection volume and the atomization efficiency of the solution. The magnitude of the injection volume further affects the intensity of the spectral line. For a fixed RF power of $1400 \mathrm{~W}$ and an atomization flow rate of $0.75 \mathrm{~L} / \mathrm{min}$, sample pumping rate of $1.4 \mathrm{~mL} / \mathrm{min}, 1.5 \mathrm{~mL} / \mathrm{min}$ and $1.6 \mathrm{~mL} / \mathrm{min}$ were selected for optimization experiments. Table 5 showed the experimental results.
From Table 5, that the concentrations in the reference were $0.194 \%$ and $0.703 \%$. When analyzed, the GBW04113 the standard deviation at a sample pumping rate of $1.6 \mathrm{~L} / \mathrm{min}$ was the smallest. When analyzed the GBW04114, standard deviation at three sample pumping rates was not very different. Therefore, the optimal sample pumping rate in the experiments was $1.6 \mathrm{~L} / \mathrm{min}$.

From the experiments, the optimal parameters for a uranium analysis using ICP-OES are the atomizer flow rate of $0.75 \mathrm{~L} / \mathrm{min}$, a sample pumping rate of $1.6 \mathrm{~mL} / \mathrm{min}$, and a $\mathrm{RF}$ power of $1400 \mathrm{~W}$.

\subsection{Verification of reference}

The five references, from GBW04110 to GBW04114, were selected to verify the accuracy of the ICP-OES analyses using the optimal parameters as listed. Table 6 shows the results for the five references with standard values between

Table 3 Results of references for different parameters

\begin{tabular}{|c|c|c|c|c|c|c|c|c|c|}
\hline Number & $\begin{array}{l}\text { RF power } \\
\text { (W) }\end{array}$ & $\begin{array}{l}\text { Atomizer } \\
\text { flow rate (L/ } \\
\text { min) }\end{array}$ & $\begin{array}{l}\text { Sample } \\
\text { pumping rate } \\
(\mathrm{mL} / \mathrm{min})\end{array}$ & $\begin{array}{l}\text { GBW04113 } \\
\text { average } \\
\text { measured } \\
\text { value }(\%)\end{array}$ & $\begin{array}{l}\text { GBW04113 } \\
\text { standard } \\
\text { value }(\%)\end{array}$ & $\begin{array}{l}\text { GBW04113 } \\
\text { relative } \\
\text { deviation } \\
(\%)\end{array}$ & $\begin{array}{l}\text { GBW04114 } \\
\text { average } \\
\text { measured } \\
\text { value }(\%)\end{array}$ & $\begin{array}{l}\text { GBW04114 } \\
\text { standard } \\
\text { value }(\%)\end{array}$ & $\begin{array}{l}\text { GBW04114 } \\
\text { relative } \\
\text { deviation (\%) }\end{array}$ \\
\hline 1 & 1200 & 0.7 & 1.8 & 0.186 & \multirow[t]{9}{*}{0.194} & 3.92 & 0.639 & \multirow[t]{9}{*}{0.703} & 9.17 \\
\hline 2 & 1200 & 0.8 & 1.5 & 0.194 & & 0.26 & 0.698 & & 0.65 \\
\hline 3 & 1200 & 0.9 & 1.2 & 0.183 & & 5.46 & 0.663 & & 5.76 \\
\hline 4 & 1300 & 0.7 & 1.2 & 0.185 & & 4.54 & 0.653 & & 7.17 \\
\hline 5 & 1300 & 0.8 & 1.8 & 0.191 & & 1.55 & 0.672 & & 4.37 \\
\hline 6 & 1300 & 0.9 & 1.5 & 0.187 & & 3.45 & 0.652 & & 7.21 \\
\hline 7 & 1400 & 0.7 & 1.5 & 0.189 & & 2.78 & 0.660 & & 6.13 \\
\hline 8 & 1400 & 0.8 & 1.2 & 0.189 & & 2.42 & 0.679 & & 3.36 \\
\hline 9 & 1400 & 0.9 & 1.8 & 0.184 & & 4.95 & 0.640 & & 8.96 \\
\hline
\end{tabular}

Table 4 Results of references at different atomizer flow rates

\begin{tabular}{lllll}
\hline $\begin{array}{l}\text { Atomizer flow rate } \\
(\mathrm{L} / \mathrm{min})\end{array}$ & $\begin{array}{l}\text { GBW04113 average } \\
\text { measured value (\%) }\end{array}$ & $\begin{array}{l}\text { Relative devia- } \\
\text { tion }(\%)\end{array}$ & $\begin{array}{l}\text { GBW04114 average } \\
\text { measured value }(\%)\end{array}$ & $\begin{array}{l}\text { Relative } \\
\text { deviation } \\
(\%)\end{array}$ \\
\hline 0.7 & 0.192 & 1.13 & 0.660 & 6.12 \\
0.75 & 0.193 & 0.62 & 0.699 & 0.57 \\
0.8 & 0.191 & 2.06 & 0.690 & 1.85 \\
0.85 & 0.190 & 2.32 & 0.688 & 2.08 \\
\hline
\end{tabular}

Table 5 Results of references at different sample pumping rates

\begin{tabular}{lllll}
\hline $\begin{array}{l}\text { Sample pumping } \\
\text { rate }(\mathrm{mL} / \mathrm{min})\end{array}$ & $\begin{array}{l}\text { GBW04113 average } \\
\text { measured value }(\%)\end{array}$ & $\begin{array}{l}\text { Relative devia- } \\
\text { tion }(\%)\end{array}$ & $\begin{array}{l}\text { GBW04114 average } \\
\text { measured value }(\%)\end{array}$ & $\begin{array}{l}\text { Relative } \\
\text { deviation } \\
(\%)\end{array}$ \\
\hline 1.4 & 0.192 & 1.03 & 0.697 & 0.697 \\
1.5 & 0.193 & 0.52 & 0.697 & 0.697 \\
1.6 & 0.194 & 0.05 & 0.702 & 0.703 \\
\hline
\end{tabular}


Table 6 ICP-OES experimental results

\begin{tabular}{llll}
\hline Sample & $\begin{array}{l}\text { ICP-OES deter- } \\
\text { mined }(\%)\end{array}$ & $\begin{array}{l}\text { Standard value } \\
(\%)\end{array}$ & $\begin{array}{l}\text { Relative } \\
\text { deviation } \\
(\%)\end{array}$ \\
\hline GBW04110 & 0.029 & 0.029 & 0.05 \\
GBW04111 & 0.080 & 0.079 & 1.27 \\
GBW04112 & 0.069 & 0.068 & 1.47 \\
GBW04113 & 0.192 & 0.194 & 1.03 \\
GBW04114 & 0.700 & 0.703 & 0.43 \\
\hline
\end{tabular}

0.0285 and $0.703 \%$ were measured using ICP-OES. The standard deviation of the results is between 0.05 and $1.47 \%$.

\subsection{Verification of rock samples}

Twenty-six rock samples with different uranium concentrations were selected for the experiments to verify the accuracy of the results obtained using ICP-OES at optimal parameters. The sample processing method described above was used to process the samples, then ICP-OES, ICP-MS, and the volumetric method were used to analyze sample solutions.

As shown in Fig. 2, 26 samples with uranium concentrations between 0.02 and $0.26 \%$ were analyzed by using ICP-OES and ICP-MS. The standard deviations of the two results were between 0.00 and $1.61 \%$. The data shows that the results obtained using ICP-OES are similar to those obtained using ICP-MS when analyzing uranium samples.

Figure 3 shows the results for 26 samples with uranium concentrations between 0.02 and $0.271 \%$ are obtained by using ICP-OES and the volumetric method. The standard deviation of the two sets of results was between 0.00 and $1.27 \%$. The results obtained using ICP-OES can be seen to be similar to those obtained using the volumetric method when analyzing uranium samples.

\subsection{Spike recovery of adding standard}

Six different samples with uranium concentrations between 350 and $1900 \mathrm{mg} / \mathrm{kg}$ were selected. 0. Samples of $0.1000 \mathrm{~g}$ were accurately weighed, pretreatment and standardization experiments were performed, and the volume was set to
Fig. 2 ICP-OES and ICP-MS experimental results

Fig. 3 Experimental results from the ICP-OES and from the volumetric method
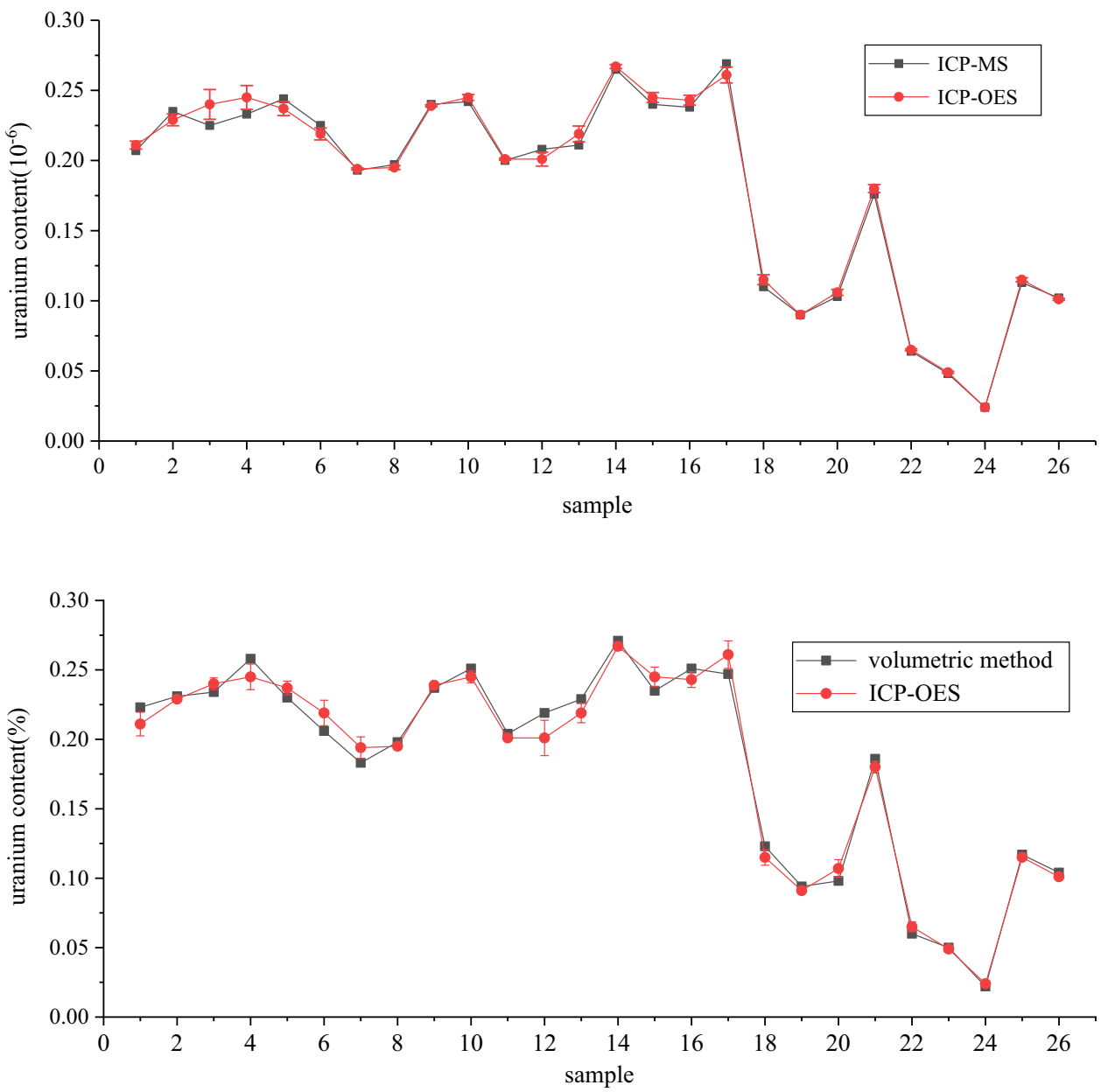
Table 7 Sample added recovery

\begin{tabular}{llllr}
\hline $\begin{array}{l}\text { Number } \\
\text { of sam- } \\
\text { ples }\end{array}$ & $\begin{array}{l}\text { Sample } \\
\text { result (mg/ } \\
\mathrm{kg})\end{array}$ & $\begin{array}{l}\text { Adding } \\
\text { standard } \\
\text { result }(\mathrm{mg} / \mathrm{L})\end{array}$ & $\begin{array}{l}\text { Adding } \\
\text { standard } \\
\text { weight }(\mathrm{mg})\end{array}$ & Recovery (\%) \\
\hline 1 & 350 & 0.821 & 0.05 & 95 \\
2 & 563 & 1.081 & 0.05 & 104 \\
3 & 849 & 1.760 & 0.1 & 91 \\
4 & 1011 & 2.11 & 0.1 & 110 \\
5 & 1575 & 3.489 & 0.2 & 96 \\
6 & 1905 & 3.837 & 0.2 & 97 \\
\hline
\end{tabular}

$100 \mathrm{~mL}$. The spike recovery was calculated based on the measurement results and concentrations. The results are shown in Table 7.

\section{Conclusion}

In this paper, we discussed the uranium concentrations of the samples analyzed by using the ICP-OES method and found that the spectrum peaks at $409.014 \mathrm{~nm}$ and $424.167 \mathrm{~nm}$ could be used for that purpose.

We tested the RF power, atomization flow rate, and sample pumping rate by using a control variate method and found the following optimal parameters an atomizer flow rate of $0.75 \mathrm{~L} / \mathrm{min}$, a sample pumping rate of $1.6 \mathrm{~mL} / \mathrm{min}$, and a high-frequency power of $1400 \mathrm{~W}$. Based on the results from the experimental samples and the references, we compared the accuracy of results achieved by using a volumetric method, ICP-MS method, and ICP-OES method with optimized parameters. The results show that convenient, quick, and effective quantitative analysis of uranium concentrations in ores.
Open Access This article is licensed under a Creative Commons Attribution 4.0 International License, which permits use, sharing, adaptation, distribution and reproduction in any medium or format, as long as you give appropriate credit to the original author(s) and the source, provide a link to the Creative Commons licence, and indicate if changes were made. The images or other third party material in this article are included in the article's Creative Commons licence, unless indicated otherwise in a credit line to the material. If material is not included in the article's Creative Commons licence and your intended use is not permitted by statutory regulation or exceeds the permitted use, you will need to obtain permission directly from the copyright holder. To view a copy of this licence, visit http://creativecommons.org/licenses/by/4.0/.

\section{References}

1. J. Katerina, S. Trajče, S. Memed-Sejfulah, B. Mirjana, U. Sonja, P. Gjorgji, DRUG Dev Ind Pharm 46, 456 (2020)

2. P. Padrón, S. Paz, C. Rubio, Á.J. Gutiérrez, D. González-Weller, A. Hardisson, Biol Trace Elem Res 194, 616 (2020)

3. T. Feyzullah, B. Sema, Int J Environ An Ch 99, 1528-1539 (2019)

4. J. Dolar-Szczasny, A. Wich, J. Flieger, M. Tatarczak-Michalewska, P. Mackiewicz, J. Proch, D. Majerek, J. Kawka, J. Macjiewicz, Molecules 24, 22 (2019)

5. A.N. Ngigi, B.M. Muraguri, Sci Afr 6, e00165 (2019)

6. V.B.K. Mullapudi, C. Krishnan, V. Gumma, K. Dheram, Microchem J 146, 807-817 (2019)

7. S. Diez-Fernández, H. Jaegler, C. Bresson, C. Frédéric, I. Hélène, Talanta 206, 120221 (2020)

8. Xu. Lina, W. Zhenyu, Z. Jian, L. Meiqi, X. Baoshan, Environe Pollut 260, 11403 (2020)

9. M. He, Su. Shaowei, B. Chen, Hu. Bin, Talanta 207, 120314 (2020)

10. O. Linderoth, P. Johansson, Mater Today Commun 20, 100538 (2019)

11. G. Heltai, Z. Gyôri, I. Fekete, G. Halász, K. Kovács, A. Takács, L. Khumalo, M. Horvátha, Microchem J 149, 104029 (2019)

12. J.A. Baker, F.K. Ayad, S.A. Maitham, Karbala Int J Mod Sci 2, 104-112 (2016)

13. N. Carrión, M. Murillo, H. Rodríguez, J. Chirinos, D. Díaz, Avances en Química 6, 61-68 (2011)

14. L.I.U. Xin, Z.A.N.G. Xufang, S.H.I. Yanhua, Sichuan Nonferrous Met 03, 41-43 (2019) 